\title{
Eficiência de uma fitase bacteriana na liberação de fósforo fítico em dietas de frangos de corte
}

\author{
[Efficiency of a bacterial phytase to release phytate phosphorus in broiler chicken diets] \\ R. Pereira ${ }^{1}$, J.F.M. Menten $^{2}$, G.G. Romano ${ }^{1}$, C.L.S. Silva ${ }^{1}$, K.C. Zavarize ${ }^{1}$, N.A.A. Barbosa ${ }^{3}$ \\ ${ }^{1}$ Aluna de pós-graduação - ESALQ/Piracicaba - Agronomia - Piracicaba, SP \\ ${ }^{2}$ ESALQ/Piracicaba - Piracicaba, SP \\ ${ }^{3}$ Pesquisa e Desenvolvimento Técnico, Ammco Pharma - Engenheiro Coelho, SP \\ RESUMO
}

\begin{abstract}
Foi avaliada a eficiência de uma fitase (FT) bacteriana na liberação de fósforo fítico utilizando-se curvas de calibração para características ósseas e de desempenho em frangos de corte. O delineamento experimental foi inteiramente ao acaso, com seis tratamentos e seis repetições até 28 dias de idade. $\mathrm{O}$ tratamento-controle foi uma dieta à base de milho e farelo de soja deficiente em fósforo $(\mathrm{P})$. Dois tratamentos corresponderam às dietas basais acrescidas de $\mathrm{P}$ suplementar, $0,05 \%$ e $0,10 \%$, e os outros à dieta basal com 66, 99 e $131 \mathrm{FTU} / \mathrm{kg}$ de ração. A curva padrão é definida pelo efeito da adição de P suplementar consumido sobre características ósseas e de desempenho, e os resultados dos tratamentos com fitase são confrontados com a curva para cálculo de $\mathrm{P}$ liberado. A adição de $\mathrm{P}$ suplementar influenciou o ganho de peso, o peso vivo e o consumo de ração de forma quadrática, bem como miligramas de cinzas ósseas de forma linear. A curva padrão adotada foi da variável miligramas de cinzas ósseas, pois a resposta linear melhor descreve a curva. As inclusões de 66, 99 e $131 \mathrm{FTU} / \mathrm{kg}$ liberaram, respectivamente, $0,048 \%, 0,049 \%$ e $0,062 \%$ de P. A fitase bacteriana é eficiente na liberação de fósforo fítico e possui viabilidade econômica.
\end{abstract}

Palavras-chave: frango de corte, fósforo disponível, cinzas ósseas, curva de calibração

\begin{abstract}
The objective was to determine the efficiency of a bacterial phytase to release phytate phosphorus using calibration curves for performance and bone characteristics in broiler chickens. A completely randomized design with 6 treatments and 6 replicates was used in an experiment with chickens from 1 to 28 days of age. The control treatment was a diet based on corn and soybean meal deficient in phosphorus. Two treatments consisted of the basal diet supplemented with additional phosphorus $(0.05 \%$ and $0.10 \%$ ), and the other treatments received 66, 99 and 131 FTU/kg of feed. The standard curves represented the effect of the levels of additional $P$ intake on performance and bone variables. Then, the responses of the phytase treatments were compared to the standard curves to calculate the $P$ released. The increasing levels of supplemental $P$ had a quadratic effect on weight gain, live weight and feed intake, and linear effect on mg of bone ash. The standard curve elected was mg of bone ash because linear response better represents the curve. Inclusion of 66, 99 and 131 FTU/kg released 0.048\%, $0.049 \%$ and $0.062 \%$. The bacterial phytase is efficient in releasing phytate, which may be of economical significance.
\end{abstract}

Keywords: broiler, available phosphorus, bone ash, standard curve

Recebido em 30 de novembro de 2010

Aceito em 14 de novembro de 2011

E-mail:rafaelazootecnia@yahoo.com.br 


\section{INTRODUÇÃO}

A avicultura tem grande importância para a economia brasileira, com produção de aproximadamente 5 milhões de postos de trabalho diretos e indiretos no país. Do total de 10,98 milhões de toneladas de carne de frango produzida, 7,297 milhões de toneladas foram destinadas ao consumo interno, de acordo com a UBA (União..., 2009). Com esses números verifica-se a importância do mercado interno para rentabilidade do setor, sendo estimado um consumo per capita de $37,8 \mathrm{~kg}$ de carne de frango/ano.

$\mathrm{Na}$ indústria avícola brasileira são necessárias, cada vez mais, pesquisas com o intuito de obter a melhor forma de utilização de nutrientes pelos animais. Assim, é possível reduzir excreções no ambiente de nutrientes, como o fósforo, e diminuir o custo das rações. Uma das maneiras de diminuir a perda de nutrientes é a inclusão de enzimas exógenas nas dietas.

Os ingredientes de origem vegetal utilizados na formulação de dieta para aves, como o milho e o farelo de soja, possuem 60 a $75 \%$ do fósforo como constituinte da molécula de fitato (Lolas et al., 1976), sendo este indisponível. O fitato é o complexo de sais de ácido fítico - mioinositol hexafosfato $\left(\mathrm{IP}_{6}\right)-$, com os minerais potássio, magnésio e cálcio, enquanto o ácido fítico é a forma livre de $\mathrm{IP}_{6}$ (Selle e Ravindran, 2007). O fósforo fítico não é aproveitado, pois as aves não sintetizam a fitase, sendo necessária a adição de maior quantidade de fósforo inorgânico na dieta para atender às exigências do animal em fósforo. Dessa forma, há aumento de fósforo nas excretas das aves tanto pela perda de fósforo fítico complexado à molécula de fitato, quanto pelo fósforo não aproveitado na forma inorgânica. Existem diversas fontes de fitase utilizadas nas indústrias de rações. A inclusão de fitase na dieta de frangos de corte aumenta a disponibilidade e o aproveitamento do fósforo fítico, assim como a digestibilidade dos alimentos.

Estudos indicam maior eficácia de liberação de fósforo fítico pela fitase de origem bacteriana em relação à de origem fúngica, uma vez que as características necessárias para ótima atividade da enzima bacteriana (Escherichia coli) são compatíveis com as características presentes no trato gastrintestinal das aves (Augspurger e
Ugalde, 2009). Há trabalhos que mostram a capacidade da fitase de aumentar a digestibilidade do fósforo da dieta e, consequentemente, o desempenho das aves (Denbow et al., 1995; Mitchel e Edwards, 1996; Singh et al., 2003), no entanto são poucos os estudos que efetivamente quantificam o fósforo liberado de ingredientes vegetais pela fitase.

A biodisponibilidade de fósforo pode ser quantificada por ensaios de digestibilidade ou pela metodologia da curva padrão, e esta última é de fácil execução e a mais utilizada (Augspurger e Ugalde, 2009).

Os objetivos deste estudo foram avaliar a eficiência de uma fitase de origem bacteriana na liberação de fósforo fítico de uma dieta baseada em milho e farelo de soja para frangos de corte, usando curvas de calibração para variáveis de desempenho e características ósseas, e comparar os critérios de resposta quanto à adequação para estimativa da liberação de fósforo, assim como a viabilidade econômica da inclusão da fitase em dietas de frangos de corte.

\section{MATERIAL E MÉTODOS}

O delineamento experimental adotado foi $\mathrm{o}$ inteiramente ao acaso, com seis tratamentos e seis repetições, de 40 aves por unidade experimental, totalizando 1440 aves. As dietas experimentais foram à base de milho e farelo de soja, conforme recomendações de Rostagno et al. (2005), com exceção do fósforo disponível, contendo diferentes porcentagens de fósforo inorgânico (Pi) na forma de fosfato bicálcico, e dietas com inclusões de fitase. O tratamentocontrole consistiu de dieta deficiente em fósforo disponível (Pd: 0,20\% e 0,15\%) para as fases de 1 a 21 e 22 a 28 dias, respectivamente. Foram utilizados mais cinco tratamentos, sendo dois correspondendo à dieta-controle acrescida de fósforo inorgânico em $0,05 \%$ e $0,10 \%$ de $\mathrm{P}$ suplementar (Tab. 1 e 2), e outros três correspondendo à dieta-controle com inclusão de 66, 99 e 131FTU/kg de ração. Os tratamentos experimentais foram: dieta basal (DB) com $0 \%$ de $\mathrm{P}$ suplementar; $0,05 \%$ de $\mathrm{P}$ suplementar; $0,10 \%$ de P suplementar; DB + 66 FTU $/ \mathrm{kg}$ de ração; $\mathrm{DB}+99$ FTU/kg de ração; $\mathrm{DB}+131$ FTU/kg de ração. 
Eficiência de uma fitase...

Tabela 1. Composição percentual e calculada da dieta basal (DB) e das dietas com P inorgânico na fase inicial (1-21 dias)

\begin{tabular}{|c|c|c|c|c|c|c|}
\hline Ingrediente & $\begin{array}{c}\text { DB } \\
0,20 \% \\
\text { Pd }\end{array}$ & $\begin{array}{c}\mathrm{DB}+0,0 \\
5 \% \mathrm{Pi}\end{array}$ & $\begin{array}{c}\mathrm{DB}+0,10 \% \\
\mathrm{Pi}\end{array}$ & $\begin{array}{l}\text { DB+66 } \\
\text { FTU/kg }\end{array}$ & $\begin{array}{l}\text { DB+99 } \\
\text { FTU/kg }\end{array}$ & $\begin{array}{l}\mathrm{DB}+131 \\
\mathrm{FTU} / \mathrm{kg}\end{array}$ \\
\hline Milho & 52,30 & 52,08 & 51,86 & 52,30 & 52,30 & 52,30 \\
\hline Farelo de soja & 40,10 & 40,14 & 40,18 & 40,10 & 40,10 & 40,10 \\
\hline Óleo de soja & 4,01 & 4,09 & 4,16 & 4,01 & 4,01 & 4,01 \\
\hline Calcário calcítico & 1,82 & 1,66 & 1,50 & 1,82 & 1,82 & 1,82 \\
\hline Fosfato bicálcico & 0,38 & 0,65 & 0,91 & 0,38 & 0,38 & 0,38 \\
\hline Sal comum & 0,51 & 0,51 & 0,51 & 0,51 & 0,51 & 0,51 \\
\hline DL-Metionina & 0,29 & 0,29 & 0,29 & 0,29 & 0,29 & 0,29 \\
\hline L-Lisina $\mathrm{HCl}$ & 0,19 & 0,18 & 0,18 & 0,19 & 0,19 & 0,19 \\
\hline L-Treonina & 0,06 & 0,06 & 0,06 & 0,06 & 0,06 & 0,06 \\
\hline Suplemento vitamínico ${ }^{1}$ & 0,10 & 0,10 & 0,10 & 0,10 & 0,10 & 0,10 \\
\hline Suplemento mineral $^{2}$ & 0,10 & 0,10 & 0,10 & 0,10 & 0,10 & 0,10 \\
\hline Agente anticoccidiano $^{3}$ & 0,05 & 0,05 & 0,05 & 0,05 & 0,05 & 0,05 \\
\hline Cloreto de colina $(60 \%)$ & 0,08 & 0,08 & 0,08 & 0,08 & 0,08 & 0,08 \\
\hline Fitase & 0 & 0 & 0 & 0,003 & 0,0045 & 0,0060 \\
\hline Total & 100,00 & 100,00 & 100,00 & 100,00 & 100,00 & 100,0 \\
\hline \multicolumn{7}{|c|}{ Composição calculada } \\
\hline \multicolumn{7}{|l|}{ Energia metabolizável } \\
\hline Proteína bruta (\%) & 23,01 & 23,01 & 23,01 & 23,01 & 23,01 & 23,01 \\
\hline Lisina dig. (\%) & 1,27 & 1,28 & 1,28 & 1,27 & 1,27 & 1,27 \\
\hline Met.+cist. dig. (\%) & 0,90 & 0,91 & 0,91 & 0,90 & 0,90 & 0,90 \\
\hline Metionina dig.(\%) & 0,60 & 0,60 & 0,60 & 0,60 & 0,60 & 0,60 \\
\hline Treonina dig. (\%) & 0,82 & 0,83 & 0,83 & 0,82 & 0,82 & 0,82 \\
\hline $\mathrm{Ca}(\%)$ & 0,90 & 0,90 & 0,90 & 0,90 & 0,90 & 0,90 \\
\hline $\operatorname{Pd}(\%)$ & 0,20 & 0,25 & 0,30 & 0,20 & 0,20 & 0,20 \\
\hline $\mathrm{K}(\%)$ & 0,88 & 0,88 & 0,81 & 0,88 & 0,88 & 0,88 \\
\hline $\mathrm{Na}(\%)$ & 0,22 & 0,22 & 0,22 & 0,22 & 0,22 & 0,22 \\
\hline \multicolumn{7}{|c|}{$\begin{array}{l}\text { IVit. A - 7.000.000,000U.I.; Vit. D3 - 2.200.000,000U.I.; Vit. E - 11.000,000mg; Vit. K - 31.600,000mg; Vit. B1 - } \\
\text { 2.000,000mg; Vit. B2 - 5.000,000mg; Vit B6 - 3.000,000mg; Vit B12 - 12.000,000mcg; Niacina (B3) - } \\
35.000,000 \mathrm{mg} \text {; Ácido pantotênico (B5) - 13.000,000mg; Ácido fólico - 800,000mg; Antioxidante - 100.000,000mg; } \\
\text { Veículo q.s.p. - 1.000,000mg. } \\
{ }^{2} \text { Cobre - 8.000,000mg; Ferro - 50.000,000mg; Manganês - 70.000,000mg; Zinco - 50.000,00mg; Iodo - 1.200,000mg; } \\
\text { Selênio - 200,000mg; Veículo q.s.p. - 1.000,000g. } \\
{ }^{3} \text { Monensina sódica 10\%. }\end{array}$} \\
\hline
\end{tabular}

A fitase utilizada foi de $2000 \mathrm{FTU} / \mathrm{g}$, e as inclusões foram 30,45 e $60 \mathrm{~g}$ de fitase por tonelada de ração, que correspondem a 60,90 e $120 \mathrm{FTU} / \mathrm{kg}$ de ração. No entanto, pela análise laboratorial da enzima, foram obtidos as quantidades de 66, 99 e 131 FTU/kg de ração. A fitase utilizada foi a 6-fitase, de origem bacteriana (E. coli) expressa na levedura Pichia pastoris.
As variáveis de desempenho e características ósseas foram usadas para a construção da curvapadrão em função do consumo de $\mathrm{P}$ suplementar, e os resultados das variáveis dos tratamentos com adição de fitase foram confrontados com a curva-padrão para serem calculados os valores de fósforo liberado. $\mathrm{O}$ consumo de $\mathrm{P}$ suplementar correspondeu ao consumo de ração $(\mathrm{g}) \times \%$ de $\mathrm{P}$ suplementar na dieta /100. 
Tabela 2. Composição percentual e calculada da dieta basal (DB) e das dietas com P inorgânico na fase de crescimento (22-28 dias)

\begin{tabular}{|c|c|c|c|c|c|c|}
\hline Ingrediente & $\begin{array}{c}\text { DB } \\
0,15 \% \\
\text { Pd }\end{array}$ & $\begin{array}{c}\mathrm{DB}+0,05 \\
\% \mathrm{Pi}\end{array}$ & $\begin{array}{c}\mathrm{DB}+ \\
0,10 \% \mathrm{Pi}\end{array}$ & $\begin{array}{l}\text { DB+66 } \\
\text { FTU/kg }\end{array}$ & $\begin{array}{l}\text { DB+99 } \\
\text { FTU/kg }\end{array}$ & $\begin{array}{l}\mathrm{DB}+131 \\
\mathrm{FTU} / \mathrm{kg}\end{array}$ \\
\hline Milho & 59,53 & 59,31 & 59,08 & 59,53 & 59,53 & 59,53 \\
\hline Farelo de soja & 33,04 & 33,08 & 33,12 & 33,04 & 33,04 & 33,04 \\
\hline Óleo de soja & 4,24 & 4,31 & 4,39 & 4,24 & 4,24 & 4,24 \\
\hline Calcário calcítico & 1,81 & 1,65 & 1,49 & 1,81 & 1,81 & 1,81 \\
\hline Fosfato bicálcico & 0,170 & 0,44 & 0,70 & 0,170 & 0,170 & 0,170 \\
\hline Sal comum & 0,48 & 0,48 & 0,48 & 0,48 & 0,48 & 0,48 \\
\hline DL-Metionina & 0,23 & 0,23 & 0,23 & 0,23 & 0,23 & 0,23 \\
\hline L-Lisina $\mathrm{HCl}$ & 0,170 & 0,17 & 0,17 & 0,170 & 0,170 & 0,170 \\
\hline L-Treonina & 0,04 & 0,04 & 0,04 & 0,04 & 0,04 & 0,04 \\
\hline Suplemento vitamínico ${ }^{1}$ & 0,09 & 0,09 & 0,09 & 0,09 & 0,09 & 0,09 \\
\hline Suplemento mineral $^{2}$ & 0,10 & 0,10 & 0,10 & 0,10 & 0,10 & 0,10 \\
\hline Agente anticoccidiano $^{3}$ & 0,05 & 0,05 & 0,05 & 0,05 & 0,05 & 0,05 \\
\hline Cloreto de colina ( $60 \%)$ & 0,06 & 0,06 & 0,06 & 0,06 & 0,06 & 0,06 \\
\hline Fitase & 0 & 0 & 0 & 0,003 & 0,0045 & 0,006 \\
\hline Total & 100,00 & 100,00 & 100,00 & 100,00 & 100,00 & 100,0 \\
\hline \multicolumn{7}{|c|}{ Composição calculada } \\
\hline \multicolumn{7}{|l|}{ Energia metabolizável } \\
\hline Proteína bruta (\%) & 20,32 & 20,32 & 20,32 & 20,32 & 20,32 & 20,32 \\
\hline Lisina dig. (\%) & 1,10 & 1,10 & 1,10 & 1,10 & 1,10 & 1,10 \\
\hline Met.+cist. dig. (\%) & 0,79 & 0,79 & 0,79 & 0,79 & 0,79 & 0,79 \\
\hline Metionina dig.(\%) & 0,51 & 0,51 & 0,51 & 0,51 & 0,51 & 0,51 \\
\hline Treonina dig. (\%) & 0,71 & 0,71 & 0,71 & 0,71 & 0,71 & 0,71 \\
\hline $\mathrm{Ca}(\%)$ & 0,83 & 0,83 & 0,83 & 0,83 & 0,83 & 0,83 \\
\hline $\operatorname{Pd}(\%)$ & 0,15 & 0,20 & 0,25 & 0,15 & 0,15 & 0,15 \\
\hline $\mathrm{K}(\%)$ & 0,77 & 0,77 & 0,77 & 0,77 & 0,77 & 0,77 \\
\hline $\mathrm{Na}(\%)$ & 0,21 & 0,21 & 0,21 & 0,21 & 0,21 & 0,21 \\
\hline \multicolumn{7}{|c|}{$\begin{array}{l}{ }^{1} \text { Vit. A - 7.000.000,000U.I.; Vit. D3 - 2.200.000,000U.I.; Vit. E - 11.000,000mg; Vit. K - 31.600,000mg; Vit. B1 - } \\
\text { 2.000,000mg; Vit. B2 - 5.000,000mg; Vit B6 - 3.000,000mg; Vit B12 - 12.000,000mcg; Niacina (B3) - } \\
35.000,000 \mathrm{mg} \text {; Ácido pantotênico (B5) - 13.000,000mg; Ácido fólico - 800,000mg; Antioxidante - 100.000,000mg; } \\
\text { Veículo q.s.p. - 1.000,000mg. } \\
{ }^{2} \text { Cobre - 8.000,000mg; Ferro - 50.000,000mg; Manganês - 70.000,000mg; Zinco - 50.000,00mg; Iodo - 1.200,000mg; } \\
\text { Selênio - 200,000mg; Veículo q.s.p. - 1.000,000g. }\end{array}$} \\
\hline
\end{tabular}

Aos 21 e 28 dias de idade, foram obtidos os dados de peso final (PF), ganho de peso (GP), consumo de ração (CR) e conversão alimentar (CA). Aos 28 dias foram selecionadas cinco aves de cada boxe com o peso médio aproximado à média de peso das aves da unidade experimental, para o abate e a coleta das tíbias. As cinco tíbias direitas de cada unidade experimental foram utilizadas para análise de cinzas ósseas, e as correspondentes tíbias esquerdas para análise de índice de Seedor e resistência óssea.
Para determinação de cinzas ósseas, as tíbias foram desengorduradas em um extrator Soxlet por aproximadamente oito horas, utilizando-se éter etílico. Em seguida, foi determinada a matéria seca dos ossos em estufa a $105^{\circ} \mathrm{C}$, e, posteriormente, as cinzas ósseas, em mufla a $600^{\circ} \mathrm{C}$, conforme a metodologia descrita por Silva (2004).

O índice de Seedor, que é o valor obtido ao se dividir o peso do osso por seu comprimento, conforme proposto por Seedor (1993), serve 
como indicativo da densidade óssea. Para análise de índice de Seedor, os ossos não foram desengordurados. Os ossos, medidos em seu maior comprimento $(\mathrm{mm})$ com um paquímetro digital, foram pesados $(\mathrm{mg})$ em uma balança semianalítica digital.

Os ossos utilizados para análise de resistência óssea foram os mesmos utilizados para análise de índice de Seedor. Para sua realização, foi utilizado o aparelho Texturômetro, TA.XT plus Texture analyser. $\mathrm{O}$ aparelho foi regulado para permitir velocidade de teste de $2 \mathrm{~mm} /$ segundo e vão livre da diáfise de $3 \mathrm{~cm}$. Este valor foi $o$ espaçamento máximo conseguido para o menor osso encontrado, sendo, dessa forma, fixado para os demais ossos do estudo. Um programa computacional registrou a força $(\mathrm{kgf})$ necessária para que ocorresse a quebra total do osso.

A análise econômica da utilização de fitase foi realizada considerando-se o custo de mercado do fosfato bicálcico e da fitase bacteriana referente ao mês de novembro de 2010 .

Os resultados das variáveis de desempenho - PF, CR, GP e CA - e de características ósseas índice de Seedor, resistência óssea e cinzas ósseas em \% e mg - foram submetidos à análise da variância pelo SAS (2006). Os resultados de todas as variáveis analisadas correspondentes aos três tratamentos com \% $\mathrm{P}$ suplementar - cálculo em relação ao consumo de $\mathrm{P}$ suplementar foram também submetidos à análise da variância e, quando a análise de variância foi significativa $(\mathrm{P}<0,05)$, realizou-se a análise de regressão polinomial por meio de polinômios ortogonais pelo SAS (2006).

\section{RESULTADOS E DISCUSSÃO}

Para construção da curva padrão, foram utilizadas dietas com quantidades reduzidas e crescentes de fósforo suplementar $0 ; 0,05 \mathrm{e}$ $0,10 \% \mathrm{P}$; sendo assim, o fósforo disponível das dietas foi mais baixo que as exigências nutricionais dos frangos. Dessa forma, conforme esperado, o desempenho dos frangos foi menor do que o desempenho obtido com níveis normais de fósforo (Tab. 3). Os animais que consumiram somente a dieta-controle (Pd inferior a $50 \%$ das exigências do mineral) apresentaram mortalidade elevada. Desta forma, para evitar perda excessiva de animais, o período experimental planejado de um a 42 dias foi reduzido para um a 28 dias de idade. Pelos mesmos motivos, deficiência mineral e mortalidade, houve desuniformidade dentro das unidades experimentais, e esse fato pode justificar os altos coeficientes de variação obtidos nas variáveis de desempenho.

As variáveis GP, PF e CR apresentaram resposta em função dos níveis de consumo de $P$ suplementar. Não existe efeito do nível de consumo de $\mathrm{P}$ suplementar sobre as características ósseas - índice de Seedor, resistência óssea e percentagem de cinzas ósseas - na tíbia dos frangos (Tab. 4). Os valores de miligramas de cinzas ósseas tiveram efeito linear, apresentando-se maiores com o aumento do consumo de P suplementar (Tab. 4).

Tabela 3. Desempenho dos frangos de corte segundo os tratamentos no período de 1 a 28 dias de idade

\begin{tabular}{cccccc}
\hline & \multicolumn{4}{c}{ Desempenho } \\
\hline $\begin{array}{c}\text { \% de P } \\
\text { suplementar }\end{array}$ & $\begin{array}{c}\text { Consumo de P } \\
\text { suplementar }(\mathrm{g})\end{array}$ & $\mathrm{PF}(\mathrm{g})^{1}$ & $\mathrm{GP}(\mathrm{g})^{1}$ & $\mathrm{CR}(\mathrm{g})^{1}$ & CA \\
\hline 0 & 0 & 867 & 812 & 1159 & 1,44 \\
0,05 & 0,772 & 1210 & 1167 & 1544 & 1,32 \\
0,10 & 1,945 & 1498 & 1456 & 1945 & 1,34 \\
$0+66$ FTU/kg & - & 1089 & 1044 & 1421 & 1,35 \\
$0+99$ FTU/kg & - & 1177 & 1131 & 1523 & 1,35 \\
$0+131$ FTU/kg & - & 1224 & 1178 & 1569 & 1,33 \\
\hline CV & & 4,65 & 4,90 & 4,79 & 4,12 \\
\hline
\end{tabular}

${ }^{\mathrm{T}}$ Resposta quadrática obtida com os três níveis crescentes de consumo de $\mathrm{P}$ suplementar $(\mathrm{p}<0,05)$ 


\section{Pereira et al.}

Tabela 4. Características ósseas dos frangos de corte de acordo com os tratamentos no período de 1 a 28 dias de idade

\begin{tabular}{|c|c|c|c|c|c|c|}
\hline \multirow[t]{2}{*}{$\%$ de $\mathrm{P}$ suplementar } & \multirow{2}{*}{$\begin{array}{c}\text { Cons. de P } \\
\text { supl.(g) }\end{array}$} & \multirow{2}{*}{$\begin{array}{l}\text { Índice de } \\
\text { Seedor }\end{array}$} & \multirow{2}{*}{$\begin{array}{l}\text { Resistência } \\
\text { óssea (kgf) }\end{array}$} & \multicolumn{2}{|c|}{ Cinzas ósseas $^{1}$} & \multirow{2}{*}{$\begin{array}{c}\% \mathrm{P} \\
\text { liberado }\end{array}$} \\
\hline & & & & $\%$ & $\mathrm{mg}^{2}$ & \\
\hline 0 & 0 & 80,6 & 14,65 & 42,2 & 830 & - \\
\hline 0,05 & 0,772 & 87,1 & 16,74 & 41,4 & 1050 & - \\
\hline 0,10 & 1,945 & 88,1 & 17,51 & 48,2 & 1450 & - \\
\hline $0+66 \mathrm{FTU} / \mathrm{kg}$ & & 81,5 & 15,61 & 43,3 & 1040 & $0,048 \%$ \\
\hline $0+99 \mathrm{FTU} / \mathrm{kg}$ & & 83,7 & 16,26 & 44,2 & 1060 & $0,049 \%$ \\
\hline $0+131 \mathrm{FTU} / \mathrm{kg}$ & - & 86,3 & 17,04 & 43,1 & 1130 & $0,062 \%$ \\
\hline $\mathrm{CV}$ & - & 6,24 & 16,08 & 5,97 & 14,59 & \\
\hline
\end{tabular}

${ }^{\mathrm{C}}$ Cinzas ósseas em base a matéria seca desengordurada.

${ }^{2}$ Resposta linear obtida com os três níveis crescentes de consumo de $\mathrm{P}$ suplementar $(\mathrm{p}<0,05), \mathrm{y}=824+316,24 \mathrm{x}$.

As variáveis de desempenho PF, GP e CR não foram os melhores parâmetros para se estimar o fósforo liberado da molécula de fitato, uma vez que apresentaram efeito quadrático. A resposta linear é a que melhor descreve a curva padrão, já que a cada aumento no eixo das abscissas corresponde um aumento no eixo das ordenadas, consequentemente as estimativas de fósforo liberado pela fitase são mais confiáveis. Portanto, a variável miligramas de cinzas ósseas na tíbia foi o melhor parâmetro obtido para se avaliar disponibilidade do $\mathrm{P}$, devido a seu comportamento linear; além disso, apresentou um coeficiente de determinação $\left(\mathrm{R}^{2}\right)$ razoável, indicativo de um bom ajuste dos dados (Tab. 5). Embora o coeficiente de determinação $\left(\mathrm{R}^{2}\right)$ da equação quadrática para a variável GP tenha sido maior que da equação linear com $\mathrm{mg}$ de cinzas ósseas (Tab. 5), este não foi o fator determinante para a escolha da equação para construção da curva padrão. $\mathrm{O}$ valor de $\mathrm{R}^{2}$ é dependente do intervalo de variabilidade na variável analisada (Montgomery et al., 2006).

Tabela 5. Respostas linear e quadrática obtidas com níveis crescentes de consumo de P suplementar $(\mathrm{g})$

\begin{tabular}{lccc} 
& & Desempenho & $\mathrm{R}^{2}$ \\
\cline { 2 - 4 } & Probabilidade & Equação & 0,97 \\
Ganho de peso & 0,0012 & $812,05+544,29 \mathrm{x}-109,46 \mathrm{x}^{2}$ & 0,98 \\
Consumo de ração & 0,0087 & $1159,27+559,34 \mathrm{x}-79,60 \mathrm{x}^{2}$ & 0,97 \\
Peso final & 0,0016 & $866,88+524 \mathrm{x}-102,29 \mathrm{x}^{2}$ & - \\
Conversão alimentar & $\mathrm{NS}$ & - & - \\
\hline & & Características ósseas & - \\
\hline Índice de Seedor & $\mathrm{NS}$ & - & - \\
Resistência óssea & $\mathrm{NS}$ & - & 0,85 \\
\% de cinzas ósseas & $\mathrm{NS}$ & $824+316,24 \mathrm{x}$ & \\
mg de cinzas ósseas & $<0,0001$ & &
\end{tabular}

NS = Não significativo a $5 \%$ de probabilidade.

Dessa forma, miligramas de cinzas ósseas foi a variável adotada para estabelecer a curva padrão. Os valores de $\mathrm{P}$ fítico liberado dos ingredientes milho e farelo de soja com as inclusões de 66, 99 e 131FTU/kg de ração foram, respectivamente, 0,048, 0,049 e 0,062\% de P (Fig. 1). Como já proposto por Nelson e Walker (1964), cinzas ósseas é considerado um dos critérios mais sensíveis para avaliar disponibilidade de $\mathrm{P}$, e também de maior precisão que ganho de peso. Esse resultado assemelha-se ao de Grimbergen et al. (1985) e Augspurger et al. (2003), que também verificaram que cinzas ósseas é o parâmetro que melhor avalia a liberação do $\mathrm{P}$ fítico da molécula de fitato. 


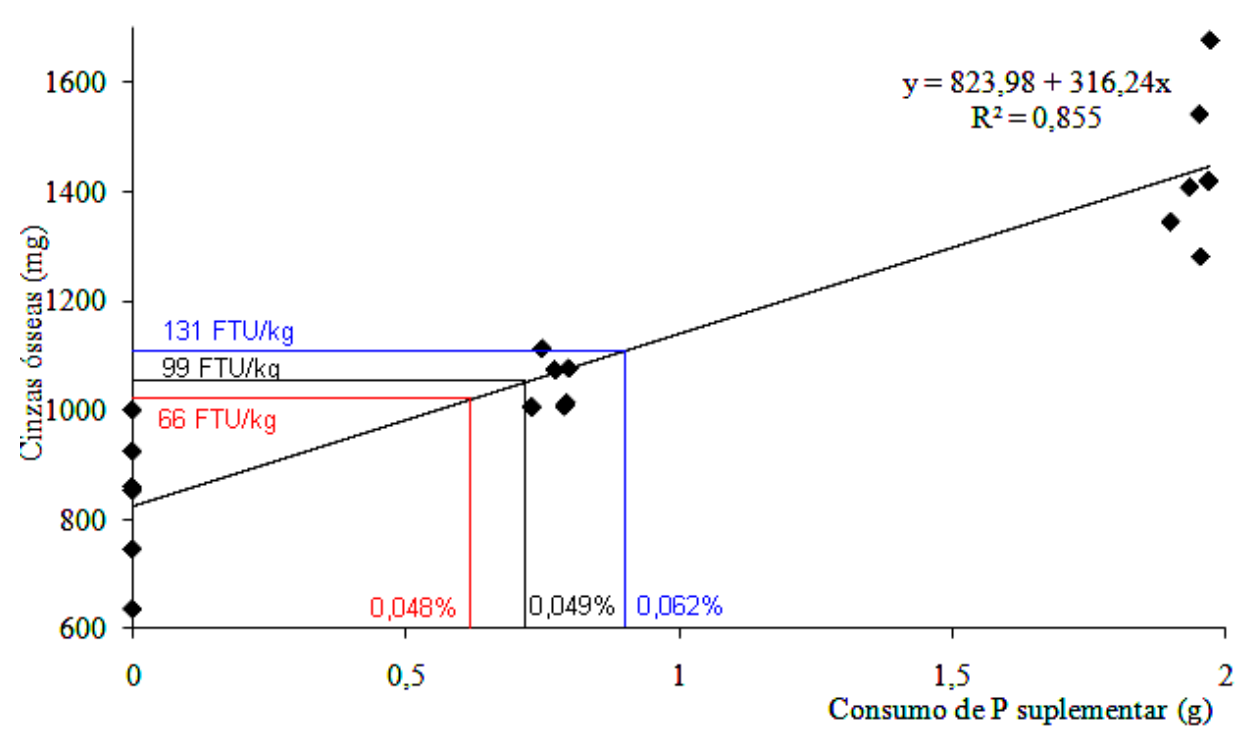

Figura 1. Curva padrão: miligramas de cinzas ósseas em função do consumo de $\mathrm{P}$ suplementar.

O cálculo de $\mathrm{P}$ liberado pela fitase utilizando-se a curva padrão é demonstrado empregando-se a variável miligramas de cinzas ósseas. A média da quantidade de miligramas de cinzas ósseas, obtida com cada inclusão de fitase, é substituída na equação, e é calculado o consumo de $\mathrm{P}$ correspondente. A razão entre o consumo de $\mathrm{P}$ correspondente e o consumo total de ração representa a porcentagem de $\mathrm{P}$ liberado pela fitase expresso em \% (Tab. 6).

Tabela 6. Média de cinzas ósseas, consumo de P suplementar, consumo de ração e P liberado de acordo com os níveis de fitase adicionados

\begin{tabular}{lccc}
\hline FTU/kg & 66 & 99 & 131 \\
\hline Cinzas ósseas (mg) & 1040 & 1060 & 1130 \\
Consumo de P suplementar $(\mathrm{g})$ & 0,684 & 0,747 & 0,968 \\
Consumo de ração (g) & 1412 & 1523 & 1569 \\
P liberado (\%) & 0,048 & 0,049 & 0,062 \\
\hline
\end{tabular}

Pelo fato de não ter ocorrido efeito dos diferentes níveis de consumo de $\mathrm{P}$ suplementar na porcentagem de cinzas ósseas, o cálculo de biodisponibilidade de $\mathrm{P}$ foi realizado somente com a variável miligramas de cinzas ósseas. Este resultado difere de outros estudos (Nelson et al., 1971; Applegate et al., 2003; Augspurger et al., 2003), os quais indicaram que resultados para cinzas ósseas, tanto em porcentagem como em miligramas, podem ser utilizados para estimar o P liberado da molécula de fitato pela fitase.

Augspurger et al. (2003) mostraram que a utilização de fitase de origem fúngica com inclusões de 500 e $1000 \mathrm{FTU} / \mathrm{kg}$ liberou de 0,026 a $0,048 \%$ de $\mathrm{P}$, e a fitase bacteriana (E. coli) com inclusão de $500 \mathrm{FTU} / \mathrm{kg}$ liberou $0,125 \%$ de P. Os resultados obtidos pela fitase bacteriana $(E$. coli) utilizando-se menores níveis de inclusão
(66, 99 e 131 FTU/kg de ração) liberaram, respectivamente, $0,048,0,049$ e $0,062 \%$ de $\mathrm{P}$ (Fig. 1). Confrontando-se os resultados obtidos de P liberado pela fitase bacteriana com a fitase fúngica avaliada por Augspurgurer et al. (2003), pode-se verificar a maior eficiência de liberação de P pela fitase bacteriana. A inclusão de fitase fúngica no nível de $1000 \mathrm{FTU} / \mathrm{kg}$ liberou a mesma quantidade de $\mathrm{P}$ que a fitase bacteriana com inclusão de apenas 66 FTU/kg. Provavelmente, um dos motivos da maior eficácia de liberação de $\mathrm{P}$ fítico pela fitase bacteriana é o fato de a enzima ser 6-fitase. A enzima 6-fitase desfosforila a molécula de fitato completamente (Wodzinki e Ullah, 1996), sendo que o mesmo fato não ocorre com fitases fúngicas que são 3 -fitase. 
A inclusão de fitase traz benefícios econômicos para produtores de frangos de corte. $\mathrm{O}$ custo da inclusão da enzima bacteriana em $131 \mathrm{FTU} / \mathrm{kg}$ de ração é de $\mathrm{R} \$ 1,48$ por tonelada. Considerando-se uma suplementação de fosfato bicálcico para atingir os mesmos $0,062 \%$ de Pd liberado pela enzima, tem-se uma necessidade de $3,35 \mathrm{~kg}$ de fosfato bicálcico/tonelada. Com preço de $\mathrm{R} \$ 1,24 / \mathrm{kg}$, o custo é de $\mathrm{R} \$ 4,16$ de fosfato bicálcico. Assim, a inclusão de 131 FTU/kg permite uma economia de $\mathrm{R} \$ 2,68$ por tonelada de ração. Além do efeito econômico, a utilização de fitase também traz benefícios para o meio ambiente. A inclusão da enzima nas dietas permite a redução de excreção de nutrientes como fósforo.

\section{CONCLUSÃO}

A quantidade de cinzas ósseas, em miligramas, é a variável de maior eficácia para estimativas de fósforo liberado pela fitase de uma dieta à base de milho e farelo de soja. A fitase bacteriana $(E$. coli) foi mais eficiente para liberar o fósforo fítico da molécula de fitato em relação à fitase de origem fúngica. A inclusão de fitase nas matrizes de formulação de ração traz benefícios econômicos e ambientais para produtores de frangos de corte.

\section{AGRADECIMENTOS}

Ao CNPq, pela concessão da bolsa de estudos; à empresa AMMCO PHARMA, pelo auxílio financeiro para o desenvolvimento do projeto.

\section{REFERÊNCIAS}

APPLEGATE, T.J.; WEBEL, D.M.; LEI, X.G. Efficacy of a phytase derived from Escherichia coli and expressed in yeast on phosphorus utilization and bone mineralization in turkeys poults. Poult. Sci., v.82, p.17261732, 2003

AUGSPURGER, N.R.; WEBEL, D.M.; LEI, X.G. et al. Efficacy of an E. coli phytase expressed in yeast for releasing phytate- bound phosphorus in young chicks and pigs. J. Anim. Sci., v.81, p.474-483, 2003.

AUGSPURGER, N.; UGALDE, E. Comparative phytase utilization in pigs and broiler chickens. In: CONGRESSO SOBRE MANEJO E NUTRIÇÃO DE AVES E SUÍNOS, 2009, Campinas. Anais... Campinas: CBNA, 2009. p.17128 .
DENBOW, D.M.; RAVINDRAN, V.; KORNEGAY, E.T. et al. Improving phosphorus availability in soyabean meal for broilers by supplemental phytase. Poult. Sci., v.74, p.1831-1842, 1995

GRIMBERGEN, A.H.M.; CORNELISSEN, J. P.; STAPPERS, H.P. The relative availability of phosphorus in inorganic feed phosphates for young turkeys and pigs. Anim. Feed Sci. Technol., v.13, p.117-130, 1985.

LOLAS, G.M.; PALAMIDIS. N.; MARKAKIS, P. The phytic acid-total phosphorus relationship in barley, oats, soybeans and wheat. Cereal Chem., v.53, p.867-871, 1976.

MITCHELL, R.D.; EDWARDS, H.M. Effect of phytase and 1,25 dihydroxycholecalciferol on phytate utilization and the quantitative requirement for calcium and phosphorus in young broiler chickens. Poult. Sci., v.75, p.95-110, 1996.

MONTGOMERY, D.C.; ELIZABETH, A.P.; VINING, G.G. Introduction to linear regression analysis. Hoboken: John Wiley, 2006. 640 p.

NELSON, T.S.; WALKER, A.C. The biological evaluation of phosphorus compounds: A summary. Poult. Sci., v.43, p.94-98, 1964.

NELSON, T. S.; SHIEH, T.R.; WODZINSKI, J. et al. Effect of supplemental phytase on the utilization of phytate phosphorus by chicks. J. Nutr., v.101, p.12891294, 1971.

ROSTAGNO, H.S.; ALBINO, L.F.T.; DONZELE, J.L. et al. Tabelas brasileiras para aves e suínos: composição de alimentos e exigências nutricionais. 2.ed. Viçosa: Universidade Federal de Viçosa, 2005. 186 p.

SAS INSTITUTE. Statistical Analysis System: user's guide. Version 9.1 ed. Cary, 2006.

SEEDOR, J.G. The biophosphanate alendronate (MK217 ) inhibit bone loss due to ovariectomy in rats. J. Bone Miner. Res., v.4, p.265-270, 1993.

SELLE, P.H.; RAVINDRAM, V. Microbial phytase in poultry nutrition. Anim. Feed Sci. Technol, v.135, p.1-41, 2007

SILVA, D.J.; QUEIROZ, A.C. Análise de alimentos: métodos químicos e biológicos. 3.ed. Viçosa: Universidade Federal de Viçosa, 2004. 235p.

SINGH, P.K.; KHATTA, V.K. Effect of phytase supplementation on the performance of broiler chickens fed wheat based diets. Indian J. Anim. Nutr., v.20, p.5762,2003

UNIÃO brasileira de avicultura. Disponível em: http://www.abef.com.br/uba/. Acessado em: 4 set. 2010.

WODZINSKI, R. J.; ULLAH, A.H.J. Phytase. Adv. Appl. Microbiol., v.42, p.263-303, 1996. 